

International Journal

for Research on

Service-Learning \&

Community Engagement

Volume 1 | Issue 1

Article 2

2013

\title{
Welcome from the IARSLCE President
}

\section{Susan Root}

This article was originally published at:

https://journals.sfu.ca/iarslce/index.php/journal/article/view/48/3

Recommended Citation

Root, S. (2013). Welcome from the IARSLCE President. International Journal of Research on Service-Learning and Community Engagement, 1(1). 


\section{Welcome from the IARSLCE President}

Dear colleague,

I am thrilled to introduce the inaugural issue of the International Journal of Research on ServiceLearning and Community Engagement (IJRSLCE), the journal of the International Association for Research on Service-Learning and Community Engagement (IARSLCE). IARSLCE is an association of K-H scholars and practitioners dedicated to the development and dissemination of high quality research on service-learning and other forms of community-based learning and collaboration. The scholarship of engagement has expanded rapidly over the past 20 years; it is now well established in higher education and youth work and, to a lesser extent, in K-12 schools. Servicelearning and community-engaged learning have also become customary practices across many academic disciplines and countries around the world. Consortia of educational institutions, community organizations and local governments are demonstrating increasingly effective ways to work together to prepare new cohorts of engaged citizens; in the context of these collaboratives, both college and non-college youth are working alongside more experienced citizens to apply democratic practices and scholarship to advance democratization and human and environmental well-being. These developments make this a perfect time for a journal that reports from this exciting field. IJRSLCE will provide researchers and practitioners with opportunities to exchange theoretical- and evidence-based advances in their work. Through IJRSLCE, researchers and practitioners will be able to access, share, build upon, and critique peer-reviewed presentations of new thinking, research questions, instrumentation, data analysis, and results in service-learning and community engagement research. By representing the range of contexts in which community-based learning occurs, IJRSLCE can give those who study and implement service-learning and community engagement an understanding of what those in their disciplines and close-to-home are learning about these practices and insight into what these practices mean when seen through alternative disciplinary lenses and when applied in other social, cultural and political settings.

On behalf of the Board of Directors of IARSLCE, I want to express our deep appreciation to Cathy Burack and Alan Melchior, IJRSLCE Editors, and to Jodi Benenson and Elizabeth Pierce, Assistant Editors, for their extensive work and thoughtfulness in securing, reviewing, and publishing the contents of this first issue of IJRSLCE. In addition, we are profoundly grateful for the solid foundation they have established for future issues of IJRSLCE, including an online presence, content for the website, advertising, a body of reviewers, and processes for review, revision, and publication.

Susan Root

IARSLCE President 